\title{
Article \\ A New Butyrate Releaser Exerts a Protective Action against SARS-CoV-2 Infection in Human Intestine
}

\author{
Lorella Paparo 1,2,*(D), Maria Antonia Maglio ${ }^{1}$, Maddalena Cortese ${ }^{1,2}$, Cristina Bruno ${ }^{1,2}$, Mario Capasso ${ }^{2,3}$ (D), \\ Erika Punzo 1,2, Veronica Ferrucci ${ }^{2,3}$, Vito Alessandro Lasorsa ${ }^{2} \mathbb{D}$, Maurizio Viscardi ${ }^{4}$, Giovanna Fusco ${ }^{4}$, \\ Pellegrino Cerino ${ }^{4}$, Alessia Romano ${ }^{2}$, Riccardo Troncone ${ }^{1}$ and Massimo Zollo ${ }^{2,3,4}$ (D)
}

1 Dipartimento di Scienze Mediche Translazionali, Università degli Studi di Napoli "Federico II", 80131 Napoli, Italy; mariantonia.maglio@unina.it (M.A.M.); Maddalenacortese95@hotmail.com (M.C.); cristinabruno88@libero.it (C.B.); pun.erika@gmail.com (E.P.); troncone@unina.it (R.T.)

2 CEINGE-Advanced Biotechnologies s.c.ar.l., Università degli Studi di Napoli "Federico II", 80131 Napoli, Italy; mario.capasso@unina.it (M.C.); veronica.ferrucci@libero.it (V.F.); lasorsa.alessandro@gmail.com (V.A.L.); romanoa@ceinge.unina.it (A.R.); massimo.zollo@unina.it (M.Z.)

3 Dipartimento di Medicina Molecolare e Biotecnologie Mediche (DMMBM), Università degli Studi di Napoli "Federico II", 80131 Napoli, Italy

4 DAI Medicina di Laboratorio e Trasfusionale, AOU Azienda Ospedaliera, Università degli Studi di Napoli “Federico II", 80131 Napoli, Italy; maurizioviscardi@gmail.com (M.V.); giovannafusco@gmail.com (G.F.); pellegrinocerino@gmail.com (P.C.)

* Correspondence: paparolorella@gmail.com

check for updates

Citation: Paparo, L.; Maglio, M.A.; Cortese, M.; Bruno, C.; Capasso, M.; Punzo, E.; Ferrucci, V.; Lasorsa, V.A.; Viscardi, M.; Fusco, G.; et al. A New Butyrate Releaser Exerts a Protective Action against SARS-CoV-2 Infection in Human Intestine. Molecules 2022, 27, 862. https://doi.org/10.3390/ molecules27030862

Academic Editor: Raffaele Capasso

Received: 15 December 2021

Accepted: 25 January 2022

Published: 27 January 2022

Publisher's Note: MDPI stays neutral with regard to jurisdictional claims in published maps and institutional affiliations.

Copyright: (c) 2022 by the authors. Licensee MDPI, Basel, Switzerland. This article is an open access article distributed under the terms and conditions of the Creative Commons Attribution (CC BY) license (https:// creativecommons.org/licenses/by/ $4.0 /)$.

\begin{abstract}
Butyrate is a major gut microbiome metabolite that regulates several defense mechanisms against infectious diseases. Alterations in the gut microbiome, leading to reduced butyrate production, have been reported in patients with severe acute respiratory syndrome coronavirus 2 (SARS-CoV-2) infection. A new butyrate releaser, useful for all the known applications of butyrate, presenting physiochemical characteristics suitable for easy oral administration, (N-(1-carbamoyl-2-phenyl-ethyl) butyramide (FBA), has been recently developed. We investigated the protective action of FBA against SARS-CoV-2 infection in the human small intestine and enterocytes. Relevant aspects of SARS-CoV-2 infection were assessed: infectivity, host functional receptor angiotensin-converting enzyme-2 (ACE2), transmembrane protease serine 2 (TMPRSS2), neuropilin-1 (NRP1), pro-inflammatory cytokines expression, genes involved in the antiviral response and the activation of Nf-kB nuclear factor (erythroid-derived 2-like) 2 (Nfr2) pathways. We found that FBA positively modulates the crucial aspects of the infection in small intestinal biopsies and human enterocytes, reducing the expression of ACE2, TMPRSS2 and NRP1, pro-inflammatory cytokines interleukin (IL)-15, monocyte chemoattractant protein-1 (MCP-1) and TNF- $\alpha$, and regulating several genes involved in antiviral pathways. FBA was also able to reduce the number of SARS-CoV-2-infected cells, and ACE2, TMPRSS2 and NRP1 expression. Lastly, through the inhibition of Nf-kB and the up-regulation of Nfr2, it was also able to reduce the expression of pro-inflammatory cytokines $I L-15, M C P-1$ and TNF- $\alpha$ in human enterocytes. The new butyrate releaser, FBA, exerts a preventive action against SARS-CoV-2 infection. It could be considered as an innovative strategy to limit COVID-19.
\end{abstract}

Keywords: COVID-19; viral infection; transmembrane protease serine 2; angiotensin-converting enzyme-2; intestinal models

\section{Introduction}

There is a global pandemic of coronavirus disease 2019 (COVID-19), caused by severe acute respiratory syndrome coronavirus 2 (SARS-CoV-2) [1]. The gastrointestinal tract is a major target organ for SARS-CoV-2 infection, with many patients presenting with gastrointestinal symptoms, such as nausea/vomiting, diarrhea and abdominal pain. These symptoms are even more frequent in severe COVID-19 patients [2,3]. 
The angiotensin-converting enzyme-2 (ACE2) and the transmembrane protease serine-2 (TMPRSS2) are two key molecules in SARS-CoV-2 infection that are highly expressed in the gastrointestinal tract $[4,5]$. In addition, neuropilin-1 (NRP1), a SARS-CoV-2 co-receptor, enhances the ability of SARS-CoV-2 to enter host cells and potentiates the infectivity of the virus [5-7]. As consequence of SARS-CoV-2 infection, host defenses launch a counterattack, releasing inflammatory cytokines, resulting in a "cytokine storm" [8]. The "cytokine storm" attempts to eliminate the virus, but, in the process, collateral damage occurs in several tissues, mainly in the gastrointestinal and respiratory tracts [9]. The inflammation induced by SARS-CoV-2 infection is also reflected by high blood levels of several inflammatory cytokines [10]. The increase in the number of inflammatory cytokines in severe COVID-19 patients is considered to be a predictor of higher mortality rate [11]. Accordingly, some successes have been reported when treating COVID-19 patients with anti-inflammatory agents [10]. Of note since now, not many drugs are known to act against the immune response that is actively induced by SARS-CoV-2 [12]. Thus, recently, phosphate food additives, including long chain PolyP, have been proven at low doses to inhibits SARS-CoV-2 infection and "the cytokine storm" [13].

Emerging evidence reports the presence of gut microbiome dysbiosis in COVID-19 patients, with a reduction of short chain fatty acids (SCFAs)-producing bacteria, such as Faecalibacterium prausnitzii [14-16]. The alteration of the gut microbiome structure (and function) seems to be higher in more severe COVID-19 patients [15]. Butyrate is major SCFAs produced by the gut microbiome, and it plays a pivotal role in human health [11]. Butyrate acts as key modulator for defense against viral infections through the modulation of several immune and non-immune mechanisms [17-19]. Butyrate is also able to exert a potent anti-inflammatory action in the gastrointestinal tract $[20,21]$. Conceptually, supplementing patients infected with SARS-CoV-2 with butyrate could serve as a helpful adjunct in preventing and treating human tissue inflammation induced by the infection. Unfortunately, the negative organoleptic profile characterized by an extremely offensive odor and taste limits the use of butyrate in human medicine and nutrition [22].

$N$-(1-carbamoyl-2-phenyl-ethyl) butyramide (FBA) is a novel butyric acid releaser, which shows physicochemical characteristics suitable for easy oral administration, being totally free of the unpleasant organoleptic properties that characterize butyrate [22]. The proposed use of FBA would accomplish two things: the direct release of butyrate into the intestinal tract, which contains one of the highest concentrations of SARS-CoV-2 receptors and increase butyrate availability for the body.

Therefore, in this study, we investigated the direct effect of FBA on the main players of SARS-CoV-2 infection: ACE2, TMPRSS2 and NRP1 [4-7], and on other key genes related to anti-viral pathways, as well as on inflammatory cytokines response in the gut.

Our results highlighted the protective role of this new butyrate releaser against host infection and inflammatory response, thus providing a scientific basis for the use of FBA against COVID-19.

\section{Results}

2.1. FBA Reduces the Expression of the Main Molecular Mediators of SARS-CoV-2 Infection and Inflammatory Cytokines in Ex Vivo and In Vitro Intestinal Models

In a first set of experiments, we investigated the direct effect of FBA on the expression of the main molecular players of SARS-CoV-2 infection: ACE2, TMPRSS2, NRP1 [4-7] and inflammatory cytokines.

We incubated human small intestine biopsy samples, collected from five healthy subjects, with FBA. We found that ACE2, TMPRSS2 and NRP1 expression, the cellular mediators that facilitate SARS-CoV-2 entry into host cells, were significantly reduced by FBA. Furthermore, FBA elicited a significant reduction in the expression of the following inflammatory cytokines: interleukin (IL)-15, monocyte chemoattractant protein-1 (MCP-1) and tumor necrosis factor (TNF)- $\alpha$ (Figure $1 \mathrm{~A})$. 


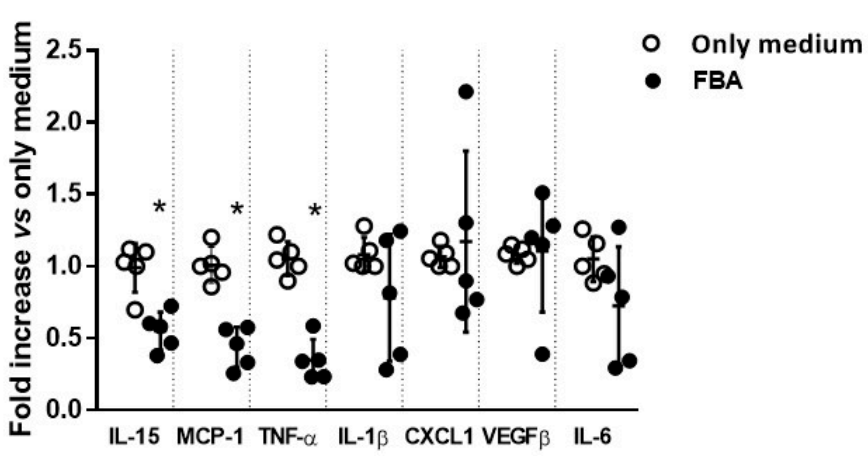

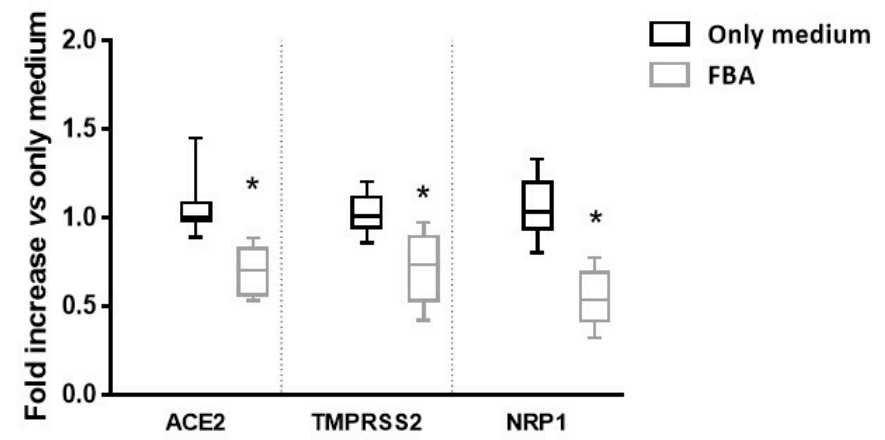

Only medium FBA

Figure 1. Effect of FBA on the main molecular players of SARS-CoV-2 infection and inflammatory cytokines expression in ex vivo and in vitro models. (A) Small intestinal biopsies from 5 healthy subjects were treated with $2 \mathrm{mM}$ FBA for $24 \mathrm{~h}$. Cells were collected for RNA extraction. FBA was able to reduce ACE2, TMPRSS2 and NRP1 (panel above) and IL-15, MCP-1, and TNF- $\alpha$ expression (panel below). (B) Caco-2 cells were treated with $2 \mathrm{mM}$ FBA for $24 \mathrm{~h}$. Cells were collected for RNA extraction. The treatment with FBA reduced ACE2, TMPRSS2 and NRP1 (panel above) and IL-15, $M C P-1$, and TNF- $\alpha$ expression (panel below). Data represent the means with \pm SD of 3 independent experiments, each performed in triplicate. Data were analyzed using a paired $t$-test. ${ }^{*} p<0.05$ vs. only medium.

Then, we moved to another set of experiments performed on the human enterocytes cell line (Caco-2 cells) to investigate the reproducibility of these effects in a different experimental model. We obtained similar results: FBA was able to significantly reduce ACE2, TMPRSS2 and IL-15, as well as MCP-1 and TNF- $\alpha$ expression in human enterocytes (Figure 1B).

\subsection{FBA Regulates the Expression of Genes Related to Anti-Viral Pathways}

To determine the effects of FBA on the transcriptional program of other key genes related to anti-viral pathways in human enterocytes, we performed high-throughput RNA sequencing. Among the genes reported in the heatmap (Figure 2), we found that FBA reduced the expression of several pivotal genes involved in anti-viral function (Supplementary Materials: Table S1): high-mobility group protein-1 (HMGB1), crucial mediator for SARS-CoV-2 replication at the post-entry phase [23]; interleukin-1 receptor-associated kinase 1 (IRAK1), responsible for the induction of the inflammatory cytokines and chemokines response associated with morbidity and mortality in COVID-19 patients [24]; the cluster of differentiation-14 (CD14), a possible target to control inflammation and organ dysfunction in SARS-CoV-2 infection [25]; TLR4, a receptor able to bind the SARS-CoV-2 spike protein, leading to the cytokine storm in severe COVID-19 patients [26]. In contrast, FBA elicited an up-regulation of the genes involved in expression in the Toll-like receptor (TLR) signaling pathway, an innate immune system targeting viruses: CHUK, an inhibitor of Nf-kB [27]; Adam17, a metallopeptidase involved in the shedding of ACE2 [28]; TRAF6, a negative 
regulator of cytokine storms [29]; interferon regulatory factor-7 (Irf7), which is inhibited in the gastrointestinal tract of COVID-19 patients [30].

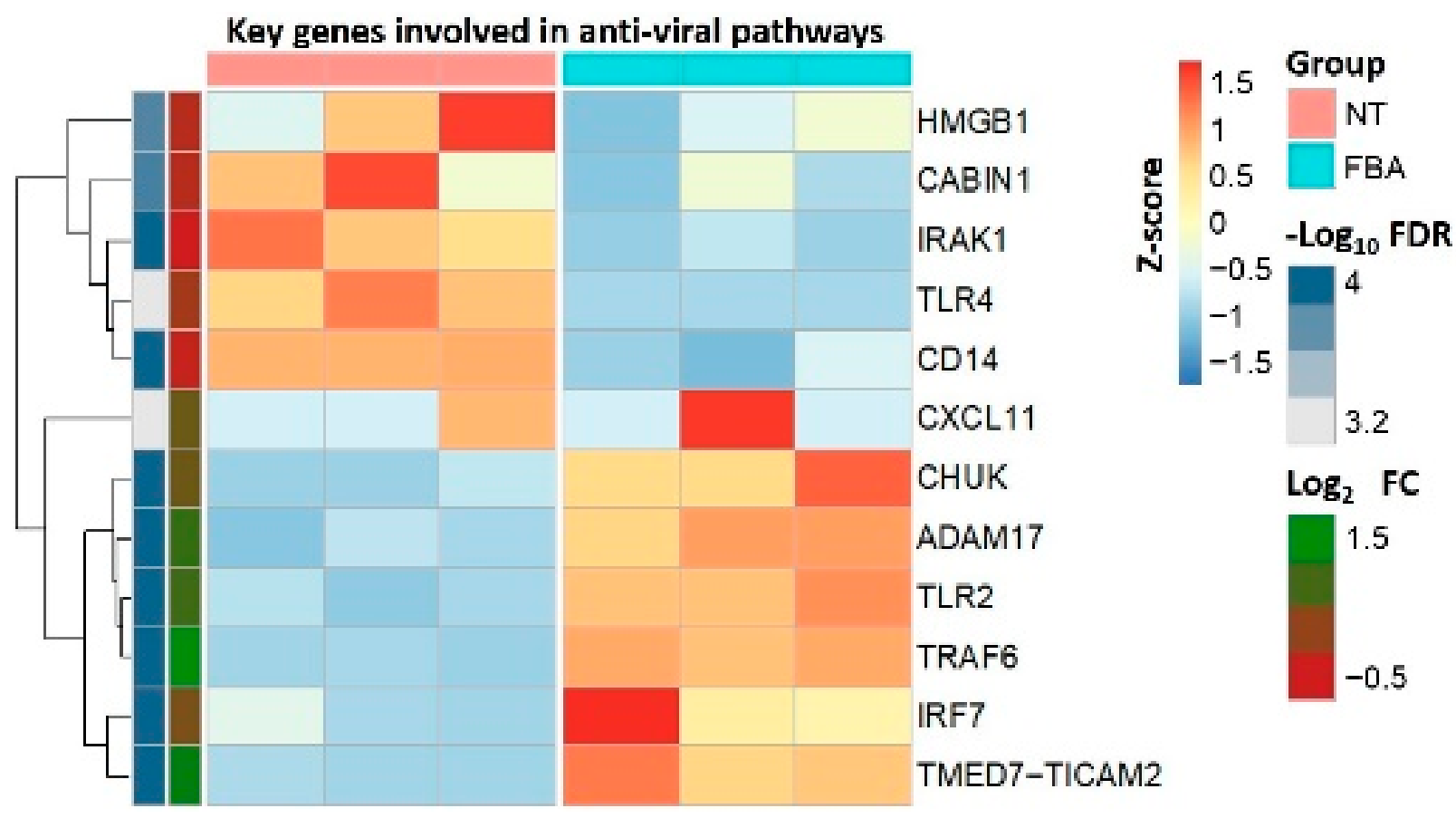

Figure 2. Effects of FBA on several genes involved in the anti-viral pathways. Heatmap reporting the average relative expression of different genes between untreated cells (NT) and 2 mM FBAstimulated human enterocytes (administered FBA for $24 \mathrm{~h}$ ). Differentially expressed genes were (i) those with a Log 2 fold change above 0.3 or below -0.3 , and an adjusted $p$-value $<0.05$ (here shown as - Log10 FDR).

\subsection{FBA Prevents the SARS-CoV-2 Infection through Nf-Kb and Nuclear Factor Erythroid} 2-Related factor 2 (Nfr2) Regulation

In the second set of experiments, we investigated the direct effect of FBA on infectivity, on ACE2, TMPRSS2 and NRP1 and on inflammatory cytokines expression in the human enterocytes infected by WT SARS-CoV-2.

We observed that FBA was able to inhibit the virus entry, as demonstrated by immunofluorescence staining and RT-PCR for the $\mathrm{N}$ viral protein (Figure 3A).

The expression of the main molecular mediators of SARS-CoV-2 infection, ACE2, TMPRSS2 and NRP1, was significantly down-regulated by FBA in WT SARS-CoV-2-infected cells (Figure 3B). Furthermore, we evaluated the expression of the most important inflammatory cytokines/chemokines commonly observed in COVID-19 patients [31], and we found that FBA was able to reduce the expression of $I L-15, M C P-1$ and TNF- $\alpha$ in human enterocytes exposed to WT SARS-CoV-2 (Figure 3C).

To investigate the mechanisms by which FBA reduces the inflammatory cytokines response, we focused on $\mathrm{Nf}-\mathrm{kB}$ activation and on antioxidant transcription factor Nfr2, both of which are involved in the regulation of inflammatory responses. It is known that SARS-CoV-2 infection triggers endoplasmic reticulum stress responses in the infected cells associated with reduced Nfr2 and increased levels of reactive oxygen species (ROS) [32]. These mechanisms trigged the "cytokine storm" through Nf-kB activation, a negative regulator of Nfr2 [32-34]. We found that FBA reduced Nf-kB activation and increased Nfr2 protein levels in human enterocytes exposed to WT SARS-CoV-2, leading to an antioxidant cellular state (Figure 3D). 
A

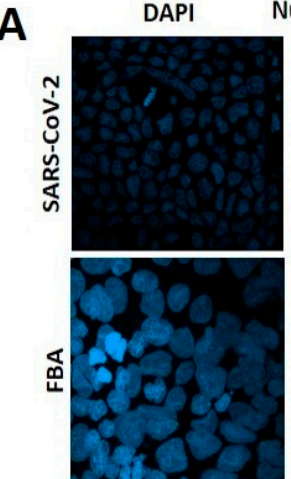

$$
\text { SARS-CoV-2 }
$$

FBA

B

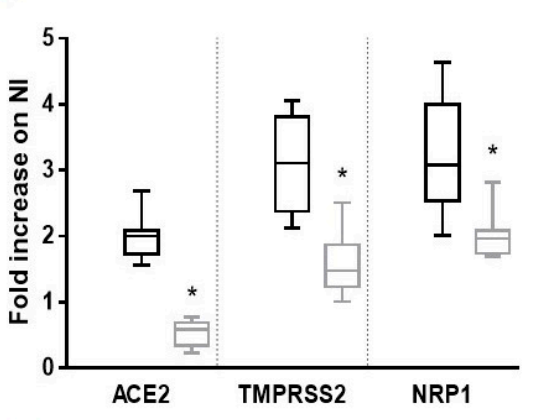

D

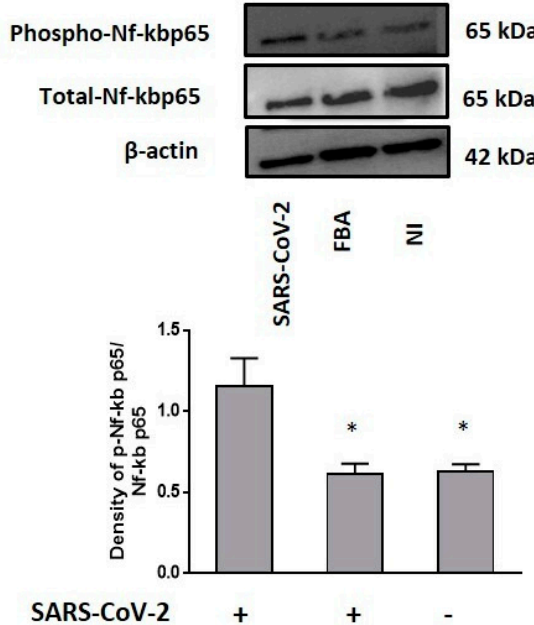

FBA

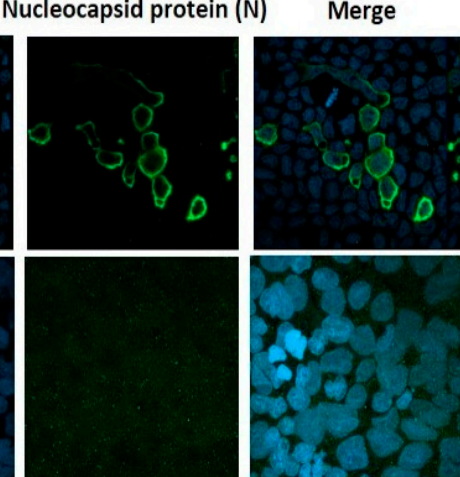

$\mathrm{N}$ protein quantization

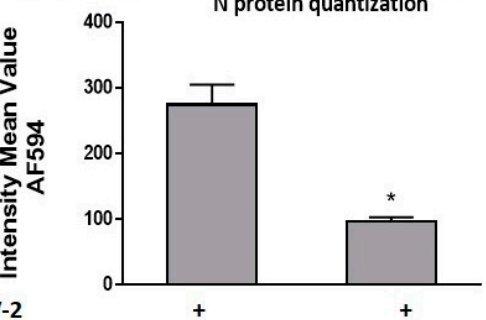

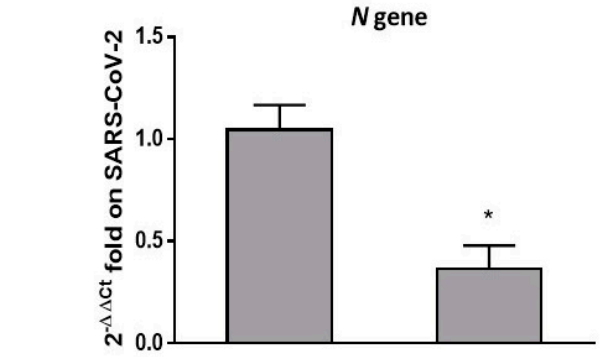

SARS-CoV-2 + +

FBA
C

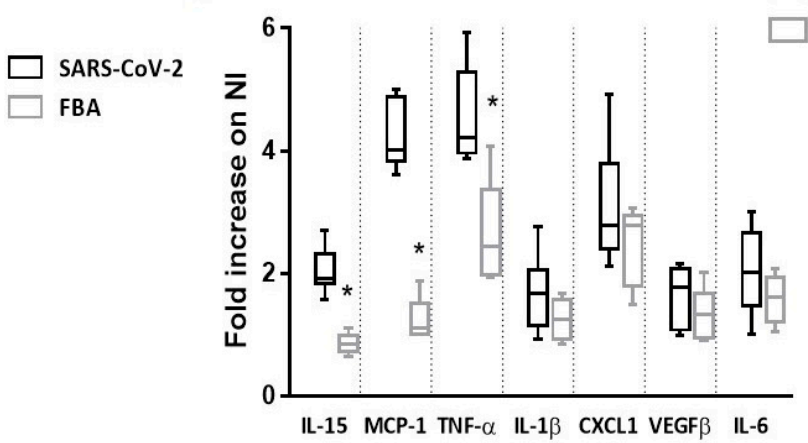

IL-15 MCP-1 TNF- $\alpha$ IL-1 $\beta$ CXCL1 VEGF $\beta$ IL- 6

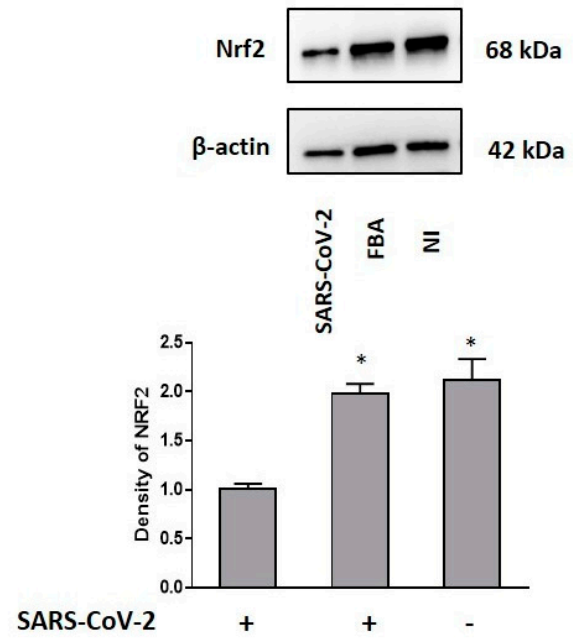

FBA

Figure 3. FBA prevented SARS-CoV-2 infection through $\mathrm{Nf}-\mathrm{Kb}$ and nuclear factor (erythroid-derived 2-like) 2 (Nfr2) regulation. (A) Caco-2 cells were infected with 0.1 MOI of WT SARS-CoV-2 that was 
pretreated with $2 \mathrm{mM}$ FBA for $24 \mathrm{~h}$. Cells were collected for RNA and protein extraction and processed for immunofluorescence. The N protein was visualized using N Alexa Fluor-594 (green) and nuclei were stained with DAPI (blue). Cells were observed through confocal microscopy (Left panel). SARS-CoV-2 infection in Caco-2 cells was confirmed by the quantification of $\mathrm{N}$ proteins by immunofluorescence staining. The pretreatment with FBA resulted in a reduction in the number of SARS-CoV-2-infected enterocytes. Representative imagines are reported in Figure 3A. Scale bar, $20 \mu \mathrm{m}$. (Right panel) The quantification of the N gene of viral RNA by RT-PCR analysis. The pretreatment with FBA inhibited N gene transcription in SARS-CoV-2-infected cells. (B) Pre-incubation with FBA significantly down-regulated ACE2, TMPRSS2 and NRP1 expression in Caco-2 cells exposed to WT SARS-CoV-2. (C) Pre-incubation with FBA significantly reduced the IL-15, MCP-1 and TNF- $\alpha$ expression in Caco-2 cells exposed to WT SARS-CoV-2. (D) Pre-incubation with FBA inhibited Nf-kB activation and increased antioxidant nuclear factor Nfr2. The amounts of these proteins and of $\beta$-actin were measured via Western blot. The histogram below shows optical density of the proteins, obtained with Image Lab software. The relative quantification of proteins was normalized against $\beta$-actin proteins and was calculated using the ratio between phosphorylated and total proteins. The figure shows representative images of three experiments that are qualitatively similar. The expression data are normalized against non-infected cells (NI). "+" or "-“ mean the presence or the absence of a particular compound. Data represent the means with \pm SD of 3 independent experiments, each performed in triplicate. Data were analyzed using a paired $t$-test. ${ }^{*} p<0.05$.

\section{Discussion}

The gastrointestinal tract is a target organ for SARS-CoV-2 infection [2,3,35]. Gut microbiome alterations, with the depletion of butyrate-producing bacteria, have been documented in SARS-CoV-2 infection, and in most patients with severe COVID-19 [14-16]. These data are not unexpected, since butyrate exerts a pivotal role in protecting the human body against infections and inflammation [21,36,37].

We explored the potential of FBA, a new butyrate releaser, against SARS-CoV-2 infection in human intestine. FBA is a palatable compound with identical functionality to natural butyrate, and it acts as a pure butyrate releaser into the human intestine, maintaining the same pharmacokinetic properties and safety profile of butyrate [22]. Previous evidence confirmed that FBA exerts a potent anti-inflammatory action in different experimental models with a similar extent of butyrate $[38,39]$.

We found that FBA was able to modulate the main players of SARS-CoV-2 infection: ACE2, TMPRSS2 and NRP-1 [4-7] and inflammatory cytokines IL-15, MCP-1 and TNF- $\alpha$ in the human intestine and enterocytes.

The results from RNA sequencing showed that FBA is also able to modulate several other mechanisms involved in SARS-CoV-2 infection, such as HMGB1, which is involved in virus replication [23], IRAK1 [24], CD14, a target to control the inflammation of COVID-19 [25] and TLR4, another receptor for the SARS-CoV-2 spike protein [26].

FBA was also able to up-regulate the expression of genes involved in the TLR signaling pathway, such as $C H U K$, an inhibitor of Nf-kB [27], TRAF6, a mediator of the inflammatory response [28] and Irf7, which is correlated with COVID-19 gastrointestinal symptoms [29].

Our data are well in line with the results of previous studies, demonstrating that butyrate positively modulates ACE2 and TMPRSS2 and the inflammatory response, and influences the expression of other anti-viral genes at the intestinal level, through an increase in acetylation of histone-H3 [40,41].

The protective effects of FBA against SARS-CoV-2 infection were confirmed also in human enterocytes. We found that this compound was able to significantly reduce the number of infected cells, as demonstrated by the reduction of $\mathrm{N}$ viral protein positive cells and their transcripts. The binding affinity of the SARS-CoV-2 spike protein and ACE2, and its cleaving through TMPRSS2, represent the major determinants of the SARS-CoV-2 replication rate [4]. SARS-CoV-2 infection is potentiated by the co-receptor NRP1, which enhances the ability of SARS-CoV-2 to enter host cells [6,7]. The blocking of viral receptorbinding domains represents a key step in anti-viral approaches [42]. We found that FBA 
was able to reduce ACE2, TMPRSS2 and NRP1 expression, preventing SARS-CoV-2 entry into human enterocytes.

The gastrointestinal tract contributes to the cytokine storm in COVID-19 patients [43]. Gut microbiota dysbiosis correlates with the high plasma concentrations of several inflammatory cytokines in COVID-19 patients [16]. The modulation of these cytokines is a relevant target to improve COVID-19 outcomes [44]. We observed that FBA was able to reduce MCP-1, IL-15 and TFN- $\alpha$. Among these cytokines, MCP- 1 and TNF- $\alpha$ could be promising biomarkers for the identification of patients at risk for severe COVID-19, representing possible targets of intervention to limit COVID-19 severity [45-47].

The analyses of three large databases of individuals with immune-mediated inflammatory diseases have demonstrated an inverse association of anti-TNF $\alpha$ use and COVID-19related outcomes [48], but further clinical trials are needed [49]. NF-kB pathway inhibition could be another potential therapeutic target for severe COVID-19 patients [50]. Its inhibition leads to the reduction of inflammatory cytokines and chemokines, such as $T N F \alpha$, $I L-1, I L-6$ and $M C P-1$, which are thought to be primarily involved in exuberant systemic inflammatory responses in COVID-19 patients [51]. It has been demonstrated that FBA, like its parental compound sodium butyrate, exerts an anti-inflammatory effect through NF-kB inhibition in DSS murine model [39]. Here, we demonstrated that FBA reduced $\mathrm{Nf}-\mathrm{kB}$ activation in SARS-CoV-2-infected enterocytes.

NF-kB and Nfr2 are key pathways regulating the balance of cellular redox status and responses to stress and inflammation [52]. The genes under the control of Nfr2 protect against stress-induced cell death, and it has been suggested that Nfr2 are the master regulators of tissue damage during infection [53]. It has been demonstrated that Nfr2 overexpression inhibited NF-kB activation [54], and the expression of Nfr2-dependent antioxidant genes is significantly inhibited in COVID-19 patients [55].

Interestingly, a positive correlation between ACE2 and Nf-kB expression has been previously demonstrated, supporting the concept that targeting Nf-kB signaling can also inhibit ACE2 expression [56].

Major limitations of our study are related to the lack of experiments with small intestinal biopsies infected with the virus, due to the short survival time of these samples in culture, and with other target cells, i.e., the respiratory tract cells, and a lack of exploration into the other immune and non-immune factors involved in SARS-CoV-2 infection.

Our data need to be validated in more complex experimental settings, and clinical trials are advocated to further explore the potential of the FBA-based strategy against COVID-19.

In conclusion, we provided evidence on the protective action elicited by the butyrate releaser FBA against COVID-19. This molecule acts on at least two mechanisms: the reduction of the number of infected cells (through a down-regulation of the expression of the main mediators of the infection: ACE2, TMPRSS2 and NRP1), and the inhibition of the cytokine storm (through an inhibition of pro-inflammatory cytokine release mediated by $\mathrm{Nfr} 2$ activation and $\mathrm{Nf}-\mathrm{Kb}$ inhibition).

Altogether, these results support the role of a healthy gut microbiome that can produce the right amount of butyrate to protect against SARS-CoV-2 infection, and support supplementing COVID-19 patients with beneficial microbial metabolites [43], with FBA as effective strategy against COVID-19.

\section{Methods}

\subsection{Virus}

Wild-type (WT) SARS-CoV-2 was isolated from the nasopharyngeal swabs of a patient with laboratory-confirmed COVID-19, as previously described [13]. Briefly, nasopharyngeal swabs in $2 \mathrm{~mL}$ of viral transport medium were collected for molecular diagnosis and frozen. Confirmed PCR-positive specimens were aliquoted and refrozen until virus isolation was initiated. Vero E6 cells were used for virus isolation from nasopharyngeal swabs. Vero E6 cells $\left(8 \times 10^{5}\right)$ were trypsinized and suspended in DMEM, with $2 \%$ FBS in T25 flasks, to which $100 \mu \mathrm{L}$ of the clinical specimen was added. The inoculated cultures were grown in a 
humidified $37{ }^{\circ} \mathrm{C}$ incubator with $5 \% \mathrm{CO}_{2}$ and observed for cytopathic effects daily. When cytopathic effects were observed ( 7 days after infection), the cell monolayers were scrapped with the back of a pipette tip. The cell culture supernatant containing the viral particles was aliquoted $(100 \mu \mathrm{L})$ and immediately frozen at $-80^{\circ} \mathrm{C}$. Viral lysates were used for total nucleic acid extraction for confirmatory testing and sequencing. Experiments involving live viruses were performed in an accredited biosafety level-3 (BSL-3) laboratory following the methodologies represented in [13].

\subsection{Human Enterocytes}

We used a well-validated model of human enterocytes, the Caco-2 cells (American Type Culture Collection, Middlesex, UK; accession number: HTB-37). This cellular model has been recently used to explore SARS-CoV-2 infection and potential therapeutic strategies against COVID-19 [57,58]. The cells were cultured in high glucose Dulbecco's modified Eagle medium (DMEM; Gibco, Berlin, Germany), supplemented with 10\% fetal bovine serum (Sigma-Aldrich; St. Louis, MO, USA), 1\% non-essential amino acids (Sigma-Aldrich; St. Louis, MO, USA), $1 \%(v / v)$ antibiotics $(10.000 \mathrm{U} / \mathrm{mL}$ penicillin and $10 \mathrm{mg} / \mathrm{mL}$ streptomycin) (Euroclone Spa; MI, Italy) and 1\% sodium pyruvate. Caco-2 cells were grown in an incubator at a temperature of $37^{\circ} \mathrm{C}$ and $\mathrm{CO}_{2}, 5 \%$. The culture medium was changed every 2 days.

\subsection{Ethics}

The study protocol, the subject information sheet, the informed consent form, and the clinical chart were reviewed and approved by the Ethics Committee of the University of Naples Federico II (N.274/17/ESCOVID19). At the baseline, written and signed informed consent was obtained from all adult participants and from all parents/tutors of the minors. The study was conducted in accordance with the Helsinki Declaration (Fortaleza revision 2013), the Good Clinical Practice Standards (CPMP/ICH/135/95), the current DecreeLaw 196/2003 regarding personal data and all the requirements set out in the European regulations on this subject.

\subsection{Organ Culture of Mucosal Biopsies from Human Small Intestine}

Small intestinal biopsies were collected via esophagogastroduodenoscopy (EGDS) from 5 healthy subjects (all Caucasian, 3 males, mean age 17 years, range 15-18 years), who had undergone an endoscopy for the presence of the following symptoms for at least 4 weeks: abdominal pain, constipation, diarrhea; and with the normal endoscopic appearance of the small intestine without histological inflammation. None of these subjects presented organic conditions.

Biopsies were used to perform organ culture experiments, as reported previously [59]. The biopsy culture was performed in RPMI-1640 medium (Sigma-Aldrich, Germany) without L-glutamine and supplemented with $10 \%$ fetal calf serum and antibiotic/antimycotic mixture (Gibco Invitrogen). Each sample was divided in two fragments for different conditions: medium alone (as the negative control) and treatment with FBA $(2 \mathrm{mM})$. The fragments were placed on a stainless-steel mesh positioned over the central well of an organ culture dish, with the villous surface of the specimens uppermost. They were cultured for $24 \mathrm{~h}$. Then, the specimens were immediately placed in RNAlater (Thermo Fisher Scientific, Waltham, MA, USA) and stored at $-80^{\circ} \mathrm{C}$ until analysis for RNA extraction.

\subsection{Cell Treatment for Basal and Infection Conditions}

For all experiments, a food grade batch of FBA, provided by Conagen Inc. (Bedford, Bedford, MA, USA), with $99.6 \%$ purity, was used. The molecular structure of FBA is depicted in Figure 4. 


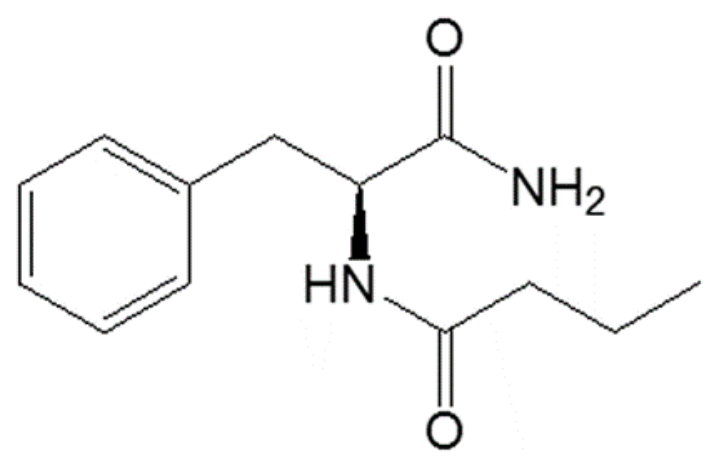

Figure 4. The molecular structure of N-(1-carbamoyl-2-phenyl-ethyl) butyramide (FBA).

To investigate the effects of FBA in basal conditions, Caco- 2 cells $\left(2 \times 10^{5}\right.$ cells / well) were seeded in 6-well plates and were treated for $24 \mathrm{~h}$ with $2 \mathrm{mM}$ FBA. Timing and dosing were selected based on the results of previous time-course and dose-response experiments performed at our laboratory. Then, the cells were washed with PBS, and harvested in TRizol for RNA extraction.

To explore the effects of FBA on the infection, Caco- 2 cells were pretreated for $24 \mathrm{~h}$ with $2 \mathrm{mM}$ FBA. Then, the cells were infected with $0.1 \mathrm{MOI}$ of viral particles that belonged to the WT SARS-CoV-2 for $72 \mathrm{~h}$. The cells were washed with PBS, and then harvested in TRizol or fixed in paraformaldehyde (PFA) for subsequent analysis. Non-infected Caco-2 cells were used as control (NI). All experiments were carried out in triplicate and for three times.

4.6. Infectivity Assays: Immunofluorescence Staining and Real-Time PCR for Nucleocapsid Protein

To determine the infectivity of SARS-CoV-2, Caco-2 cells were fixed with $4 \%$ PFA (Carlo Erba Reagents, MI, Italy) for $10 \mathrm{~min}$ at room temperature and processed for immunofluorescence staining to visualize viral antigen expression (Nucleocapsid protein, $\mathrm{N})$. Autofluorescence due to free aldehyde groups from PFA treatment were blocked with $50 \mathrm{mM}$ ammonium chloride (Sigma-Aldrich, St. Louis, MO, USA) in PBS for 10 min at room temperature. Cover slips were washed twice with PBS, and then cells were permeabilized with $0.1 \%$ Triton X-100 (PanReac AppliChem, Milan, Italy) in PBS for 10 min. After washing, the cells were blocked for $1 \mathrm{~h}$ using $1 \%$ BSA in PBS/0.2\% Tween 20, and then incubated overnight at $4{ }^{\circ} \mathrm{C}$ with a specific primary antibody for Nucleoprotein (1:100; ProSci, 3851). Coverslips were washed with PBS and incubated with horseradish peroxidase (HRP)conjugated goat anti-mouse (1:500; Alexa Fluor 594, A21203, Invitrogen, MA, USA) for $1 \mathrm{~h}$ at RT. Nuclei were stained with $4^{\prime} 6$-Diamidino-2-phenylindole dihydrochloride (DAPI) (Invitrogen). Finally, cells were mounted with antifading Mowiol (Sigma-Aldrich). Cells were observed with a 63x objective on a Zeiss LSM980 confocal system equipped with an ESID detector and controlled by Zen blue software (Zeiss; Jena, Germany).

To detect the $\mathrm{N}$ gene in infected Caco-2 cells, total RNA was isolated with a TRizol reagent (Sigma-Aldrich), according to the manufacturer's instructions. The RNA samples were quantified using the NanoDrop 2000c spectrophotometer (Thermo Scientific, Waltham, MA, USA) and RNA quality and integrity were assessed with the Experion RNA Standard Sense kit (Bio-Rad, Hercules, CA, USA). The RT-PCR for N of SARS-CoV-2 was performed with a Liferiver Novel Coronavirus (2019-nCoV) Real-Time kit (BioVendor, Brno, Czech Republic). These runs were performed using a 7900 Real-Time PCR System (Applied Biosystems, Carlsbad, CA, USA) under the following conditions: $45^{\circ} \mathrm{C}$ for $10 \mathrm{~min}, 95^{\circ} \mathrm{C}$ for $3 \mathrm{~min}$, and $95^{\circ} \mathrm{C}$ for $15 \mathrm{~s}$ and $58^{\circ} \mathrm{C}$ for $30 \mathrm{~s}(\times 45$ cycles).

The quantification cycle values of $\mathrm{N}$ are reported as means $\pm \mathrm{SD}$ normalized to the internal control provided by the kit. 
4.7. SARS-CoV-2 Molecular Mediators and Inflammatory Cytokine Analyses with Quantitative Real-Time PCR

A part of the RNA extracted (500 ng) was reverse transcribed in cDNA with a HighCapacity RNA-to-cDNATM Kit (Thermofisher, Waltham, MA, USA) according to the manufacturer's instructions. Complementary DNA (cDNA) was stored at $-80{ }^{\circ} \mathrm{C}$ until use.

To evaluate the effect on ACE2, TMPRSS2 and NRP1 gene expression, a quantitative real-time PCR (qRT-PCR) analysis was performed using a TaqMan Gene Expression Master Mix (Hs00174179_m1, Hs01122322_m1 and Hs00826128_m1, respectively; Thermofisher).

Inflammatory cytokines expression (IL-6, IL-15, IL-1 $\beta, V E G F \beta, T N F-\alpha, M C P-1$ and CXCL1) was evaluated using a SYBR green Master Mix (Applied Biosystems, Grand Island, NY, USA). The details of the primers used in these assays are provided in Table 1 . The cDNAs were amplified using a 7900 Real-Time PCR System (Applied Biosystems) at the following cycling conditions: $50^{\circ} \mathrm{C}$ for $2 \mathrm{~min}, 95^{\circ} \mathrm{C}$ for $2 \mathrm{~min}, 40$ cycles of $95^{\circ} \mathrm{C}$ for $15 \mathrm{~s}$ and $60{ }^{\circ} \mathrm{C}$ for $1 \mathrm{~min}$, followed by the melt curve setting of 1 cycle of $95^{\circ} \mathrm{C}$ for $15 \mathrm{~s}, 60^{\circ} \mathrm{C}$ for $1 \mathrm{~min}$ and $95^{\circ} \mathrm{C}$ for $15 \mathrm{~s}$.

Table 1. Sequences of the primers to analyze pro-inflammatory cytokines.

\begin{tabular}{|c|c|c|}
\hline Gene & Primer & Primer Sequence \\
\hline \multirow[t]{2}{*}{$I L-6$} & Forward & CTCGACGGCATCTCAGCC \\
\hline & Reverse & GCCTCTTTGCTGCTTTCACAC \\
\hline \multirow[t]{2}{*}{ IL-15 } & Forward & CAGTTGCAAAGTAACAGCAATGAA \\
\hline & Reverse & GCATCTCCGGACTCAAGTGAA \\
\hline \multirow[t]{2}{*}{$I L-1 \beta$} & Forward & CTTTGAAGCTGATGGCCCTAA \\
\hline & Reverse & CGCCATCCAGAGGGCAG \\
\hline \multirow[t]{2}{*}{$V E G F \beta$} & Forward & AGAAGGAGGAGGGCAGAATCA \\
\hline & Reverse & GATGGCAGTAGCTGCGCTG \\
\hline \multirow[t]{2}{*}{$T N F-\alpha$} & Forward & CTTCTGCCTGCTGCACTTTG \\
\hline & Reverse & TGATTAGAGAGAGGTCCCTGGG \\
\hline \multirow[t]{2}{*}{$M C P 1$} & Forward & CTATAGAAGAATCACCAGCAGCAGCAAGT \\
\hline & Reverse & TCTCCTTGGCCACAATGGTC \\
\hline \multirow[t]{2}{*}{ CXCL1 } & Forward & GCGCCCAAACCGAAGTCATA \\
\hline & Reverse & ATGGGGGATGCAGGATTGAG \\
\hline
\end{tabular}

Data analysis was performed using the comparative threshold cycle (CT) method and expressed as 2^-delta CT [25]. The beta-glucuronidase (GUSB) gene was used as the housekeeping gene (forward primer: 5'-GAAAATATGTGGTTGGAGAGCTCATT-3'; reverse primer: $5^{\prime}$-CCGAGTGAAGATCCCCTTTTTA-3'). Expression data were normalized to non-infected cells (NI). Each sample was analyzed in triplicate.

\section{8. cDNA Library Construction for RNA Sequencing Analysis}

To investigate the influence of FBA on the expression on the antiviral-related gene, another part of the RNA extract ( $1 \mu \mathrm{g}$ ) was used for RNA sequencing (RNA-Seq) analysis. The RNA sample quality was assessed with an Agilent 2100 Bioanalyzer RNA Nano chip device (Agilent, Santa Clara, CA, USA), and total RNA concentrations were determined using a NanoDrop ND1000 spectrophotometer (Nano-Drop, Wilmington, DE, USA). Agarose Gel Electrophoresis was also performed to test RNA degradation and potential contamination.

After the QC procedures, mRNAs were enriched using oligo(dT) beads. The mRNAs were mixed with the fragmentation buffer and broken into short fragments ( $200 \mathrm{bp}$ long). Then, the first strand of cDNA was synthesized with random hexamer primers. The second strand was synthesized using the SuperScript Double-Stranded cDNA Synthesis kit (Invitrogen, Camarillo, CA, USA) and was purified via magnetic beads. The ends were repaired and tailed with a single $3^{\prime}$ adenosine. Subsequently, the cDNA fragments were ligated to sequencing adapters. Quality controls of the obtained libraries were performed with Qubit 2.0 to test the library concentration preliminarily, Agilent 2100 to test the insert size and Q-PCR to precisely quantify the effective library concentration. 


\subsection{RNA-Seq Data Analysis}

The analysis started with Illumina Paired End reads (FASTQ format) that were previously filtered by adapter sequences, with low-quality reads and with reads with more than $10 \%$ of unknown bases.

The quality assessment of cleaned FASTQ files was performed using FastQC (http:/ / www.bioinformatics.babraham.ac.uk/projects / fastqc, accessed on 1 April 2014). Cleaned reads were of high quality; the percentage of bases with quality scores above 20 and 30 (Q20 and Q30) were 97.6 and 93.6 percent, respectively (Table 2).

Table 2. Full description of RNA-Seq data analyses.

\begin{tabular}{cccccccc}
\hline Sample ID & Analysis ID & Total Reads (M) & $\begin{array}{c}\text { Read } \\
\text { Length }\end{array}$ & $\begin{array}{c}\text { Q20 } \\
\mathbf{( \% )}\end{array}$ & $\begin{array}{c}\text { Q30 } \\
\text { (\%) }\end{array}$ & $\begin{array}{c}\text { Overall Mapping } \\
\text { Rate (\%) }\end{array}$ & $\begin{array}{c}\text { Paired Mapping } \\
\text { Rate (\%) }\end{array}$ \\
\hline NT1 & NT_0 & 86.24 & 150 & 97.6 & 93.5 & 92.5 & 88.0 \\
NT2 & NT_1 & 85.33 & 150 & 97.7 & 93.7 & 92.6 & 88.1 \\
NT3 & NT_2 & 90.58 & 150 & 97.5 & 93.4 & 92.5 & 88.1 \\
\hline FBA1_2 mM & FBA_1_0 & 90.10 & 150 & 97.7 & 93.7 & 92.5 & 87.9 \\
FBA2_2 mM & FBA_1_1 & 79.95 & 150 & 97.7 & 93.8 & 92.3 & 87.7 \\
FBA3_2 mM & FBA_1_2 & 82.92 & 150 & 97.8 & 93.9 & 92.7 & 88.2 \\
\hline
\end{tabular}

Sequencing data were analyzed with the Tuxedo suite tool set (TopHat v2.0.14 and Cufflinks v2.1.0) following the analysis pipeline published in nature protocols 2012. TopHat is a fast splice junction mapper for RNA-Seq reads. It aligns RNA-Seq reads to the reference genome using the ultra-high throughput short read aligner Bowtie2 v2.2.6.0, and then analyzes the mapping results to identify the splice junctions between exons. TopHat was run with default options by providing the reference genome (assembly GRCh37/hg19, downloaded from UCSC and indexed with Bowtie2) and its related RefSeq reference transcriptome (downloaded from UCSC), along with the couple of FASTQ files (forward and reverse reads) for each sample. The alignment versus the reference genome (GRCh37/hg19 assembly) had an overall mapping rate of $92.49 \%$, as shown in Table 2.

Next, Cufflinks was used to assemble the mapped reads (in the BAM file format) into possible transcripts and to generate a final transcriptome assembly. The tool Cuffmerge was exploited to merge transcriptomes from all samples and generate a common transcriptome file. Cuffdiff was finally used to detect differentially expressed genes and transcripts. It takes mapped reads from two or more biological conditions (provided as two or more biological replicates) and analyzes their differential expression of genes and transcripts, thus aiding in the investigation of their transcriptional and post transcriptional regulation under different conditions. The program was run by providing all the obtained BAM files (specifying the experimental condition and the replicate to which they belonged), the merged transcriptome assembly and the sequence of the reference genome. The software returned FPKM normalized counts (Fragments Per Kilobase of Exon Per Million Fragments Mapped) for each replicate and averaged FPKM counts for each experimental condition. Cuffdiff also assesses the statistical significance. Briefly, it performs a two-sided test for significance against a null hypothesis that the log-transformed ratio of the expression is unity (no change). The set of output files obtained by Cuffdiff was then inspected and explored using the R-Bioconductor package CummeRbund v2.16.0, which provides functions to read, subset, filter and plot results. Differentially expressed genes were those with a Log 2 fold change above 0.5 or below -0.5 and an adjusted $p$ value $<0.05$. Among the differentially expressed genes, we focused on the antiviral pathways [40].

\subsection{Western Blotting for $N f-k B$ and $N f r 2$ Protein Detection}

Western blotting was performed on the total protein extracts of infected Caco- 2 cells pretreated with FBA. For the total protein fraction, the harvested cells were washed in cold phosphate-buffered saline (PBS) and lysed in protein lysis buffer (RIPA). Protein 
concentrations in cell extracts were determined using the Bradford assay (BioRad, Milan, Italy). Thirty micrograms of total lysates were loaded onto 10\% SDS-PAGE and then transferred to nitrocellulose membranes (ImmobilonR-Transfer Membrane, Tullagreen, Carrigtwohill, Co). The membranes were blocked with 5\% non-fat milk in PBS, pH 7.6, 0.2\% Tween 20 (PanReac AppliChem) and probed overnight at $4{ }^{\circ} \mathrm{C}$ with the specific primary antibodies for Nf-KB p65 (1:1000; Cell Signaling, MA, USA) and Nfr2 (1:1000, \#89443, AbCam, Cambridge, UK). After washing in PBS, pH 7.6 and 0.2\% Tween 20, the membranes were incubated with a horseradish peroxidase-conjugated goat anti-rabbit antibody (1:2000; Abcam). The immunoblots were visualized using ECL detection kits, with enhanced chemiluminescence (Pierce, Rockford, IL, USA). A mouse $\beta$-actin antibody (1:5000; Elabscience) was used as the control for equal loading of total lysates.

\subsection{Statistical Analysis}

The Kolmogorov-Smirnov test was used to determine whether variables were normally distributed. Descriptive statistics were reported as means and standard deviations (SDs) for continuous variables. To evaluate the differences among continuous variables, an independent sample $t$-test was performed. The level of significance for all statistical tests was two-sided, $p<0.05$. All data were collected in a dedicated database and analyzed by a statistician using GraphPad Prism 7 (La Jolla, CA, USA).

Supplementary Materials: The following are available online, Table S1: Raw data of expression of genes related to anti-viral pathways regulated by FBA; Figure S1: Full-length gel of Phosfo-Nf-kBp65, Total Nf-kBp65 and $\beta$-actin; Figure S2: Full-length gel of Nrf-2 and $\beta$-actin.

Author Contributions: Credit of authorship contribution statement: L.P.: conceptualization, data curation, methodology, software, validation, writing —original draft, writing-review and editing. M.A.M.: investigation, validation. M.C. (Maddalena Cortese): methodology, software, supervision. C.B.: methodology, software, supervision. M.C. (Mario Capasso): conceptualization, funding acquisition, validation, writing-original draft, writing-review and editing. E.P.: investigation, methodology, validation. V.F.: investigation, supervision, validation. V.A.L.: formal analysis, software, investigation, validation. M.V.: investigation, methodology, validation. G.F.: investigation, methodology, validation. P.C.: investigation, methodology, validation. A.R.: formal analysis, software, investigation, validation. R.T.: conceptualization, data curation, validation. M.Z.: conceptualization, funding acquisition, validation, supervision, project administration, writing - original draft, writing - review and editing. All authors approved the final manuscript as submitted and agree to be accountable for all aspects of the work. All authors have read and agreed to the published version of the manuscript.

Funding: This work was supported by the project "CEINGE Task Force COVID19," code D64I200003800 by Regione Campania for the fight against COVID-19 (DGR no. 140; 17 March 2020) and "CIRO Project: infrastructures and scientific instrumentation", devoted to the CEINGE-Advanced Biotechnologies at the University of Naples "Federico II". However, Regione Campania and CIRO Project had no influence on: (1) the study design; (2) the collection, analysis, and interpretation of data; (3) the writing of the manuscript; and (4) the decision to submit the manuscript for publication.

Institutional Review Board Statement: The study was conducted in accordance with the Declaration of Helsinki, and approved by Ethics Committee of the University of Naples Federico II (N.274/17/ESCOVID19; 28 May 2020).

Informed Consent Statement: Informed consent was obtained from all subjects involved in the study.

Data Availability Statement: The datasets used and/or analyzed during the current study are available from the corresponding author on reasonable request.

Acknowledgments: We thank Caterina Missero, supervisor of the Advanced Light Microscopy (ALM) Facility at CEINGE-Advanced Biotechnologies, University of Naples "Federico II", for the support during the immunofluorescence analyses.

Conflicts of Interest: The authors have no other conflict of interests that are directly relevant to the content of this manuscript, which remains their sole responsibility. 
Sample Availability: Samples of the compounds are available from the authors.

\section{References}

1. Atzrodt, C.L.; Maknojia, I.; McCarthy, R.D.P.; Oldfield, T.M.; Po, J.; Ta, K.T.L.; Stepp, H.E.; Clements, T.P. A Guide to COVID-19: A global pandemic caused by the novel coronavirus SARS-CoV-2. FEBS J. 2020, 287, 3633-3650. [CrossRef] [PubMed]

2. Liu, Y.; Yan, L.-M.; Wan, L.; Xiang, T.-X.; Le, A.; Liu, J.-M.; Peiris, M.; Poon, L.L.M.; Zhang, W. Viral dynamics in mild and severe cases of COVID-19. Lancet Infect. Dis. 2020, 20, 656-657. [CrossRef]

3. Cheung, K.S.; Hung, I.F.N.; Chan, P.P.Y.; Lung, K.C.; Tso, E.; Liu, R.; Ng, Y.Y.; Chu, M.Y.; Chung, T.W.H.; Tam, A.R.; et al. Gastrointestinal Manifestations of SARS-CoV-2 Infection and Virus Load in Fecal Samples From a Hong Kong Cohort: Systematic Review and Meta-analysis. Gastroenterology 2020, 159, 81-95. [CrossRef]

4. Hoffmann, M.; Kleine-Weber, H.; Schroeder, S.; Krüger, N.; Herrler, T.; Erichsen, S.; Schiergens, T.S.; Herrler, G.; Wu, N.-H.; Nitsche, A.; et al. SARS-CoV-2 Cell Entry Depends on ACE2 and TMPRSS2 and Is Blocked by a Clinically Proven Protease Inhibitor. Cell 2020, 181, 271-280.e8. [CrossRef]

5. Berni Canani, R.; Comegna, M.; Paparo, L.; Cernera, G.; Bruno, C.; Strisciuglio, C.; Zollo, I.; Gravina, A.G.; Miele, E.; Cantone, E.; et al. Age-Related Differences in the Expression of Most Relevant Mediators of SARS-CoV-2 Infection in Human Respiratory and Gastrointestinal Tract. Front. Pediatr. 2021, 9, 697390. [CrossRef] [PubMed]

6. Cantuti-Castelvetri, L.; Ojha, R.; Pedro, L.D.; Djannatian, M.; Franz, J.; Kuivanen, S.; van der Meer, F.; Kallio, K.; Kaya, T.; Anastasina, M.; et al. Neuropilin-1 facilitates SARS-CoV-2 cell entry and infectivity. Science 2020, 370, 856-860. [CrossRef]

7. $\quad$ Daly, J.L.; Simonetti, B.; Klein, K.; Chen, K.-E.; Williamson, M.K.; Antón-Plágaro, C.; Shoemark, D.K.; Simón-Gracia, L.; Bauer, M.; Hollandi, R.; et al. Neuropilin-1 is a host factor for SARS-CoV-2 infection. Science 2020, 370, 861-865. [CrossRef]

8. Mehta, P.; McAuley, D.F.; Brown, M.; Sanchez, E.; Tattersall, R.S.; Manson, J.J.; HLH Across Speciality Collaboration, UK. COVID-19: Consider cytokine storm syndromes and immunosuppression. Lancet 2020, 395, 1033-1034. [CrossRef]

9. Liao, M.; Liu, Y.; Yuan, J.; Wen, Y.; Xu, G.; Zhao, J.; Cheng, L.; Li, J.; Wang, X.; Wang, F.; et al. Single-cell landscape of bronchoalveolar immune cells in patients with COVID-19. Nat. Med. 2020, 26, 842-844. [CrossRef]

10. Zhang, W.; Zhao, Y.; Zhang, F.; Wang, Q.; Li, T.; Liu, Z.; Wang, J.; Qin, Y.; Zhang, X.; Yan, X.; et al. The use of anti-inflammatory drugs in the treatment of people with severe coronavirus disease 2019 (COVID-19): The Perspectives of clinical immunologists from China. Clin. Immunol. 2020, 214, 108393. [CrossRef]

11. Zhou, F.; Yu, T.; Du, R.; Fan, G.; Liu, Y.; Liu, Z.; Xiang, J.; Wang, Y.; Song, B.; Gu, X.; et al. Clinical course and risk factors for mortality of adult inpatients with COVID-19 in Wuhan, China: A retrospective cohort study. Lancet 2020, 395, 1054-1062. [CrossRef]

12. Peter, A.E.; Sandeep, B.V.; Rao, B.G.; Kalpana, V.L. Calming the Storm: Natural Immunosuppressants as Adjuvants to Target the Cytokine Storm in COVID-19. Front. Pharmacol. 2021, 11, 583777. [CrossRef]

13. Ferrucci, V.; Kong, D.-Y.; Asadzadeh, F.; Marrone, L.; Boccia, A.; Siciliano, R.; Criscuolo, G.; Anastasio, C.; Quarantelli, F.; Comegna, M.; et al. Long-chain polyphosphates impair SARS-CoV-2 infection and replication. Sci. Signal. 2021, 14, eabe5040. [CrossRef]

14. Zuo, T.; Zhang, F.; Lui, G.C.Y.; Yeoh, Y.K.; Li, A.Y.L.; Zhan, H.; Wan, Y.; Chung, A.C.K.; Cheung, C.P.; Chen, N.; et al. Alterations in Gut Microbiota of Patients with COVID-19 during Time of Hospitalization. Gastroenterology 2020, 159, 944-955.e8. [CrossRef]

15. Gu, S.; Chen, Y.; Wu, Z.; Chen, Y.; Gao, H.; Lv, L.; Guo, F.; Zhang, X.; Luo, R.; Huang, C.; et al. Alterations of the Gut Microbiota in Patients With Coronavirus Disease 2019 or H1N1 Influenza. Clin. Infect. Dis. 2020, 71, 2669-2678. [CrossRef]

16. Yeoh, Y.K.; Zuo, T.; Lui, G.C.-Y.; Zhang, F.; Liu, Q.; Li, A.Y.; Chung, A.C.; Cheung, C.P.; Tso, E.Y.; Fung, K.S.; et al. Gut microbiota composition reflects disease severity and dysfunctional immune responses in patients with COVID-19. Gut 2021, 70, 698-706. [CrossRef]

17. Zheng, D.; Liwinski, T.; Elinav, E. Interaction between microbiota and immunity in health and disease. Cell Res. 2020, 30, 492-506. [CrossRef]

18. Schuijt, T.J.; Lankelma, J.M.; Scicluna, B.P.; Melo, F.D.S.E.; Roelofs, J.J.T.H.; de Boer, J.D.; Hoogendijk, A.J.; de Beer, R.; de Vos, A.; Belzer, C.; et al. The gut microbiota plays a protective role in the host defence against pneumococcal pneumonia. Gut 2016, 65, 575-583. [CrossRef]

19. Haak, B.W.; Littmann, E.R.; Chaubard, J.-L.; Pickard, A.; Fontana, E.; Adhi, F.; Gyaltshen, Y.; Ling, L.; Morjaria, S.M.; Peled, J.; et al. Impact of gut colonization with butyrate producing microbiota on respiratory viral infection following allo-HCT. Blood 2018, 131, 2978-2986. [CrossRef]

20. Coppola, S.; Avagliano, C.; Calignano, A.; Canani, R.B. The Protective Role of Butyrate against Obesity and Obesity-Related Diseases. Molecules 2021, 26, 682. [CrossRef]

21. Berni Canani, R.; Di Costanzo, M.; Leone, L.; Pedata, M.; Meli, R.; Calignano, A. Potential beneficial effects of butyrate in intestinal and extraintestinal diseases. World J. Gastroenterol. 2011, 17, 1519-1528. [CrossRef]

22. Russo, R.; Santarcangelo, C.; Badolati, N.; Sommella, E.; De Filippis, A.; Dacrema, M.; Campiglia, P.; Stornaiuolo, M.; Daglia, M. In vivo bioavailability and in vitro toxicological evaluation of the new butyric acid releaser $N$-(1-carbamoyl-2-phenyl-ethyl) butyramide. Biomed. Pharmacother. 2021, 137, 111385. [CrossRef]

23. Wei, J.; Alfajaro, M.M.; Hanna, R.E.; DeWeirdt, P.C.; Strine, M.S.; Lu-Culligan, W.J.; Zhang, S.-M.; Graziano, V.R.; Schmitz, C.O.; Chen, J.S.; et al. Genome-wide CRISPR screen reveals host genes that regulate SARS-CoV-2 infection. bioRxiv 2020. [CrossRef] 
24. Stoy, N. Involvement of Interleukin-1 Receptor-Associated Kinase 4 and Interferon Regulatory Factor 5 in the Immunopathogenesis of SARS-CoV-2 Infection: Implications for the Treatment of COVID-19. Front. Immunol. 2021, 12, 638446. [CrossRef]

25. Martin, T.R.; Wurfel, M.M.; Zanoni, I.; Ulevitch, R. Targeting innate immunity by blocking CD14: Novel approach to control inflammation and organ dysfunction in COVID-19 illness. EBioMedicine 2020, 57, 102836. [CrossRef]

26. Conte, C. Possible Link between SARS-CoV-2 Infection and Parkinson's Disease: The Role of Toll-Like Receptor 4. Int. J. Mol. Sci. 2021, 22, 7135. [CrossRef]

27. Neurath, M.F.; Becker, C.; Barbulescu, K. Role of NF-kB in immune and inflammatory responses in the gut. Gut 1998, 43, 856-860. [CrossRef]

28. Palau, V.; Riera, M.; Soler, M.J. ADAM17 inhibition may exert a protective effect on COVID-19. Nephrol. Dial. Transpl. 2020, 35, 1071-1072. [CrossRef] [PubMed]

29. Liu, N.; Tang, B.; Wei, P.; Sun, W.; Wang, S.; Peng, Q. TRAF6-mediated degradation of DOK3 is required for production of IL-6 and TNF $\alpha$ in TLR9 signaling. Mol. Immunol. 2015, 68, 699-705. [CrossRef] [PubMed]

30. Blanco-Melo, D.; Nilsson-Payant, B.E.; Liu, W.-C.; Uhl, S.; Hoagland, D.; Møller, R.; Jordan, T.X.; Oishi, K.; Panis, M.; Sachs, D.; et al. Imbalanced Host Response to SARS-CoV-2 Drives Development of COVID-19. Cell 2020, 181, 1036-1045.e9. [CrossRef] [PubMed]

31. Coperchini, F.; Chiovato, L.; Croce, L.; Magri, F.; Rotondi, M. The cytokine storm in COVID-19: An overview of the involvement of the chemokine/chemokine-receptor system. Cytokine Growth Factor Rev. 2020, 53, 25-32. [CrossRef] [PubMed]

32. Fung, T.S.; Liao, Y.; Liu, D.X. Regulation of Stress Responses and Translational Control by Coronavirus. Viruses 2016, 8, 184. [CrossRef] [PubMed]

33. Yu, M.; Li, H.; Liu, Q.; Liu, F.; Tang, L.; Li, C.; Yuan, Y.; Zhan, Y.; Xu, W.; Li, W.; et al. Nuclear factor p65 interacts with Keap1 to repress the Nrf2-ARE pathway. Cell. Signal. 2011, 23, 883-892. [CrossRef] [PubMed]

34. Neufeldt, C.J.; Cerikan, B.; Cortese, M.; Frankish, J.; Lee, J.Y.; Plociennikowska, A.; Heigwer, F.; Joecks, S.; Burkart, S.S.; Zander, D.Y.; et al. SARS-CoV-2 infection induces a pro-inflammatory cytokine response through cGAS-STING and NF-kB. bioRxiv 2020. [CrossRef] [PubMed]

35. Cholankeril, G.; Podboy, A.; Aivaliotis, V.I.; Tarlow, B.; Pham, E.A.; Spencer, S.P.; Kim, D.; Hsing, A.; Ahmed, A. High Prevalence of Concurrent Gastrointestinal Manifestations in Patients With Severe Acute Respiratory Syndrome Coronavirus 2: Early Experience From California. Gastroenterology 2020, 159, 775-777. [CrossRef] [PubMed]

36. Trompette, A.; Gollwitzer, E.S.; Pattaroni, C.; Lopez-Mejia, I.C.; Riva, E.; Pernot, J.; Ubags, N.; Fajas, L.; Nicod, L.P.; Marsland, B.J. Dietary fiber confers protection against flu by shaping Ly6c-patrolling monocyte hema topoiesis and CD8+ T cell metabolism. Immunity 2018, 48, 992-1005. [CrossRef] [PubMed]

37. Lu, W.; Fang, Z.; Liu, X.; Li, L.; Zhang, P.; Zhao, J.; Zhang, H.; Chen, W. The Potential Role of Probiotics in Protection against Influenza a Virus Infection in Mice. Foods 2021, 10, 902. [CrossRef]

38. Raso, G.M.; Simeoli, R.; Russo, R.; Iacono, A.; Santoro, A.; Paciello, O.; Ferrante, M.C.; Canani, R.B.; Calignano, A.; Meli, R. Effects of Sodium Butyrate and Its Synthetic Amide Derivative on Liver Inflammation and Glucose Tolerance in an Animal Model of Steatosis Induced by High Fat Diet. PLoS ONE 2013, 8, e68626. [CrossRef]

39. SSimeoli, R.; Raso, G.M.; Pirozzi, C.; Lama, A.; Santoro, A.; Russo, R.; Montero-Melendez, T.; Canani, R.B.; Calignano, A.; Perretti, M.; et al. An orally administered butyrate-releasing derivative reduces neutrophil recruitment and inflammation in dextran sulphate sodium-induced murine colitis. J. Cereb. Blood Flow Metab. 2017, 174, 1484-1496. [CrossRef]

40. Li, J.; Richards, E.M.; Handberg, E.M.; Pepine, C.J.; Raizada, M.K. Butyrate Regulates COVID-19-Relevant Genes in Gut Epithelial Organoids from Normotensive Rats. Hypertension 2021, 77, e13-e16. [CrossRef]

41. Elce, A.; Amato, F.; Zarrilli, F.; Calignano, A.; Troncone, R.; Castaldo, G.; Canani, R.B. Butyrate modulating effects on proinflammatory pathways in human intestinal epithelial cells. Benef. Microbes. 2017, 8, 841-847. [CrossRef] [PubMed]

42. Huang, Y.; Yang, C.; Xu, X.-F.; Xu, W.; Liu, S.-W. Structural and functional properties of SARS-CoV-2 spike protein: Potential antivirus drug development for COVID-19. Acta Pharmacol. Sin. 2020, 41, 1141-1149. [CrossRef] [PubMed]

43. Archer, D.L.; Kramer, D.C. The Use of Microbial Accessible and Fermentable Carbohydrates and/or Butyrate as Supportive Treatment for Patients with Coronavirus SARS-CoV-2 Infection. Front. Med. 2020, 7, 292. [CrossRef] [PubMed]

44. Qian, G.; Zhang, Y.; Xu, Y.; Hu, W.; Hall, I.P.; Yue, J.; Lu, H.; Ruan, L.; Ye, M.; Mei, J. Reduced inflammatory responses to SARS-CoV-2 infection in children presenting to hospital with COVID-19 in China. EClinicalMedicine 2021, 34, 100831. [CrossRef]

45. Jørgensen, M.J.; Holter, J.C.; Christensen, E.E.; Schjalm, C.; Tonby, K.; Pischke, S.E.; Jenum, S.; Skeie, L.G.; Nur, S.; Lind, A.; et al. Increased interleukin-6 and macrophage chemoattractant protein-1 are associated with respiratory failure in COVID-19. Sci. Rep. 2020, 10, 21697. [CrossRef]

46. Tay, M.Z.; Poh, C.M.; Rénia, L.; Macary, P.A.; Ng, L.F.P. The trinity of COVID-19: Immunity, inflammation and intervention. Nat. Rev. Immunol. 2020, 20, 363-374. [CrossRef]

47. Del Valle, D.M.; Kim-Schulze, S.; Huang, H.-H.; Beckmann, N.D.; Nirenberg, S.; Wang, B.; Lavin, Y.; Swartz, T.H.; Madduri, D.; Stock, A.; et al. An inflammatory cytokine signature predicts COVID-19 severity and survival. Nat. Med. 2020, 26, 1636-1643. [CrossRef]

48. Mahil, S.K.; Dand, N.; Mason, K.J.; Yiu, Z.Z.; Tsakok, T.; Meynell, F.; Coker, B.; McAteer, H.; Moorhead, L.; Mackenzie, T.; et al. Factors associated with adverse COVID-19 outcomes in patients with psoriasis-Insights from a global registry-based study. J. Allergy Clin. Immunol. 2021, 147, 60-71. [CrossRef] 
49. Feldmann, M.; Maini, R.N.; Woody, J.N.; Holgate, S.T.; Winter, G.; Rowland, M.; Richards, D.; Hussell, T. Trials of anti-tumour necrosis factor therapy for COVID-19 are urgently needed. Lancet 2020, 395, 1407-1409. [CrossRef]

50. Brenner, E.J.; Ungaro, R.C.; Gearry, R.B.; Kaplan, G.G.; Kissous-Hunt, M.; Lewis, J.D.; Ng, S.C.; Rahier, J.-F.; Reinisch, W.; Ruemmele, F.M.; et al. Corticosteroids, But Not TNF Antagonists, Are Associated With Adverse COVID-19 Outcomes in Patients With Inflammatory Bowel Diseases: Results From an International Registry. Gastroenterology 2020, 159, 481-491.e3. [CrossRef]

51. Kircheis, R.; Haasbach, E.; Lueftenegger, D.; Heyken, W.T.; Ocker, M.; Planz, O. NF-кB Pathway as a Potential Target for Treatment of Critical Stage COVID-19 Patients. Front. Immunol. 2020, 11, 598444. [CrossRef] [PubMed]

52. Wardyn, J.D.; Ponsford, A.H.; Sanderson, C.M. Dissecting molecular cross-talk between Nrf2 and NF- $\mathrm{kB}$ response pathways. Biochem. Soc. Trans. 2015, 43, 621-626. [CrossRef] [PubMed]

53. Soares, M.P.; Ribeiro, A.M. Nrf2 as a master regulator of tissue damage control and disease tolerance to infection. Biochem. Soc. Trans. 2015, 43, 663-668. [CrossRef] [PubMed]

54. Cuadrado, A.; Martín-Moldes, Z.; Ye, J.; Lastres-Becker, I. Transcription Factors NRF2 and NF-kB Are Coordinated Effectors of the Rho Family, GTP-binding Protein RAC1 during Inflammation. J. Biol. Chem. 2014, 289, 15244-15258. [CrossRef]

55. Olagnier, D.; Farahani, E.; Thyrsted, J.; Blay-Cadanet, J.; Herengt, A.; Idorn, M.; Hait, A.; Hernaez, B.; Knudsen, A.; Iversen, M.B.; et al. SARS-CoV2-mediated suppression of NRF2-signaling reveals potent antiviral and anti-inflammatory activity of 4-octyl-itaconate and dimethyl fumarate. Nat. Commun. 2020, 11, 4938. [CrossRef]

56. Yan, M.; Dong, Y.; Bo, X.; Cheng, Y.; Cheng, J. Large Screening Identifies ACE2 Positively Correlates With NF-кB Signaling Activity and Targeting NF-кB Signaling Drugs Suppress ACE2 Levels. Front. Pharmacol. 2021, 12, 771555. [CrossRef]

57. Shuai, H.; Chu, H.; Hou, Y.; Yang, D.; Wang, Y.; Hu, B.; Huang, X.; Zhang, X.; Chai, Y.; Cai, J.P.; et al. Differential immune activation profile of SARS-CoV-2 and SARS-CoV infection in human lung and intestinal cells: Implications for treatment with IFN- $\beta$ and IFN inducer. J. Infect. 2020, 81, e1-e10. [CrossRef]

58. Chu, H.; Chan, J.F.; Yuen, T.T.; Shuai, H.; Yuan, S.; Wang, Y.; Hu, B.; Yip, C.C.; Tsang, J.O.; Huang, X.; et al. Comparative tropism, replication kinetics, and cell damage profiling of SARS-CoV-2 and SARS-CoV with implications for clinical manifestations, transmissibility, and laboratory studies of COVID-19: An observational study. Lancet Microbe 2020, 1, e14-e23. [CrossRef]

59. Vitale, S.; Strisciuglio, C.; Pisapia, L.; Miele, E.; Barba, P.; Vitale, A.; Cenni, S.; Bassi, V.; Maglio, M.; Del Pozzo, G.; et al. Cytokine production profile in intestinal mucosa of paediatric inflammatory bowel disease. PLoS ONE 2017, 12, e0182313. [CrossRef] 